\title{
BMJ Open Developing Objective Metrics for Unit Staffing (DOMUS) study
}

\author{
I Siddiqui, ${ }^{1}$ B Whittingham, ${ }^{1} \mathrm{~K}$ Meadowcroft, ${ }^{1}$ M Richardson, ${ }^{1} \mathrm{~J} \mathrm{C}$ Cooper, ${ }^{1}$ \\ J Belcher, ${ }^{2}$ E Morris, ${ }^{3}$ K M K Ismail ${ }^{4,5}$
}

To cite: Siddiqui I, Whittingham B, Meadowcroft K, et al. Developing Objective Metrics for Unit Staffing (DOMUS) study. BMJ Open 2014;4: e005398. doi:10.1136/ bmjopen-2014-005398

- Prepublication history for this paper is available online. To view these files please visit the journal online (http://dx.doi.org/10.1136/ bmjopen-2014-005398).

Received 3 April 2014 Revised 11 August 2014 Accepted 12 August 2014

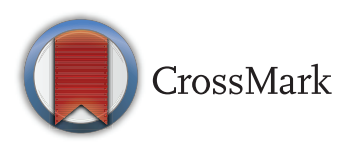

${ }^{1}$ University Hospital of North Staffordshire NHS Trust, Stoke, UK

${ }^{2}$ Department of Primary Care Sciences, Arthritis Research UK Primary Care Centre, Keele University,

Staffordshire, Keele, UK

${ }^{3}$ Norfolk and Norwich

University Hospital NHS

Foundation Trust, Norwich,

UK

${ }^{4}$ College of Medical \& Dental Sciences, Birmingham centre for Women's and Children's Health, School of Clinical \& Experimental Medicine, University of Birmingham, Birmingham, UK ${ }^{5}$ Birmingham Women's NHS Foundation Trust, Birmingham, UK

Correspondence to Professor KMK Ismail; k.ismail@bham.ac.uk

\section{ABSTRACT}

Objective: Safe midwifery staffing levels on delivery suites is a priority area for any maternity service. Escalation policies are tools that provide an operational response to emergency pressures. The aim of this study was to assess the feasibility of using a scoring system to contemporaneously assess the required staffing level based on demand and use this to determine delivery suite escalation level and utilise the information generated regarding clinical activity (Demand) and staffing levels (Capacity) to generate unit-specific calculation for the actual number of midwifery staff required.

Setting: A maternity unit of a university-affiliated tertiary referral hospital.

Design: Over a 12-month period, specifically designed scoring sheets were completed by delivery suite shift co-ordinators four times a day (04:00, 10:00, 16:00 and 22:00). Based on the dependency score (Demand) and the number of midwifery staff available (Capacity), an escalation level was determined for each shift. The 80th centile of the demand was used to determine optimal capacity.

Results: A total of 1160 scoring sheets were completed. Average staff number throughout the year on any shift was 7 (range 3-11). Average dependency score was 7 (range 1-14). The 80th centile for demand was calculated to be 11 .

Conclusions: This study stresses the importance and usefulness of a simple tool that can be used to determine the level of escalation on delivery suite based on an objective scoring system and can also be used to determine the appropriate staffing on delivery suite.

\section{INTRODUCTION}

Appropriate levels of midwifery staffing on delivery suites (DS) tend to be an ongoing concern across maternity units in the UK. It has implications on the safety and quality of intrapartum care provided and impacts on staff morale, job satisfaction, staff sickness rates and their recruitment and retention within maternity services. ${ }^{1-3}$ One-to-one midwifery care for women in labour is a standard of maternity care recommended by the Royal
Strengths and limitations of this study

- Escalation policies are tools that provide an operational response to emergency pressures.

- Birth Rate Plus $\left(\mathrm{BR}^{+}\right)$is a validated, real-time objective measure of the number of midwives required to provide a high-quality maternity service at any point in time on delivery suite.

- Developing Objective Metrics for Unit Staffing (DOMUS) provides a simple tool that can be used to determine the level of escalation on delivery suite and appropriate staffing levels required for the safe and efficient service delivery on a labour ward.

- Benefit could be added through an evaluation of the impact of this training on the usability of the scoring system or inter-rater variability.

College of Midwives (RCM) and the Royal College of Obstetricians and Gynaecologists (RCOG) in their joint document 'Safer Childbirth' ${ }^{4}$ and by the National Institute for Health and Care Excellence (NICE) ${ }^{5}$ Determining staffing capacity on any acute service delivery department is usually based on average patient turnover using retrospective data and does not necessarily reflect realtime fluctuations in demand. Indeed, activity can vary throughout the week and even from time to time during 1 day.

Escalation policies are tools that provide an operational response to emergency pressures. ${ }^{6}$ The main aim of escalation is to provide a rapid, consistent and predictable resolution of the triggering situation thereby reducing the risk of further escalation and allowing resumption of normal working as quickly as possible. The labour ward escalation policy, discussed in this report, was originally produced in response to a request from the Trust board clinical governance committee to ensure safe staffing levels on labour ward at all times, particularly in the event of heightened clinical activity and to provide clear guidance to key staff about actions required to mitigate any potential clinical risks, which are frequently associated 
with a busy work environment. Therefore, to ensure validity and effectiveness of this tool, it was imperative to ensure that the measure of clinical activity is objective, clinically plausible and reproducible.

Intrapartum scoring based on mother and baby care needs was originally developed in 1986 where the score reflected the level of clinical complexity and hence demand. The methodology was applied in several maternity services and extensive validation of the dependency scores was carried out. Recently, Birth Rate Plus $\left(\mathrm{BR}^{+}\right)$ was developed and validated as a real-time objective measure of the number of midwives required to provide a high-quality maternity service at any point in time on DS. The principle is based on the knowledge that women with higher care needs require more than 1:1 midwife time to care for them while on labour ward. ${ }^{78}$ Hence, the total $\mathrm{BR}^{+}$score at anytime on labour ward determines the minimum number of midwives expected to be available to provide intrapartum care at that time point. In an attempt to reduce the subjectivity and determine the level of escalation of DS in a busy maternity unit, we conceived the idea of using a modified $\mathrm{BR}^{+}$ scoring system to contemporaneously assess the required staffing level (dependency score) based on demand and use this score to determine DS escalation level. To our knowledge, this idea and the development of the escalation policy preceded the National Patient Safety Agency (NPSA) labour ward scorecard. ${ }^{9}{ }^{10}$ The main aims of the Developing Objective Metrics for Unit Staffing (DOMUS) study were to assess the feasibility of using a modified $\mathrm{BR}^{+}$scoring approach to determine the level of DS escalation and utilise the information generated regarding clinical activity (Demand) and staffing levels (Capacity) to generate unit-specific calculation for the actual number of midwifery staff required to deliver a high-quality service using a validated capacity and demand model.

\section{METHODS}

The study was undertaken in the maternity unit of a university-affiliated tertiary referral hospital that serves a population of approximately 600000 with an in-house level 3 neonatal unit and a delivery rate of approximately 6000 maternities per annum. Throughout the time of the study, the RCM's recommended staffing standard of 28 births: 1 whole time equivalent midwife was maintained. During the study period there was always an aim to have 12 midwives at any given shift. However, for various reasons, staffing pressures throughout the unit were encountered.

Following agreement from the Trust clinical governance board, piloting the escalation policy was originally introduced in June 2009. It was initially planned to score capacity and demand (figure 1) 12 hourly. However, following a 6-month pilot phase, DS staff felt that twice daily scoring failed to capture the activity pattern and trends. This led to an update in the policy with instigation of a six hourly scoring system. An adapted $\mathrm{BR}^{+}$was used as an objective measure for demand. The main reason for the modification was to ensure that it is suitable for all women who are cared for on DS. At the time of the study most of the women undergoing a prostaglandin induction of labour (PGL-IOL) were admitted to labour ward for the duration of their induction and subsequent labour. However, IOL is not represented as a category in $\mathrm{BR}^{+}$(as an intrapartum scoring system it only accounts for women in labour); hence, a new category was added to the score sheet for women undergoing PGL-IOL. Although 1:1 care is not required during the early stages of induction, women would still need some degree of midwifery input while on the unit. Scoring sheets were completed by DS shift co-ordinators four times a day (04:00, 10:00, 16:00 and 22:00). Based on the dependency score determined by the number and clinical needs of women on DS (Demand) in relation to the number of midwifery staff available (Capacity), an escalation level was determined for each shift. A traffic light system was used to display the escalation level on the labour ward board for all staff to be aware (table 1).

Data were entered into an Excel spreadsheet and analysed. Capacity and demand was studied by drawing the data on a control chart using Statistical Process Control (SPC). ${ }^{11}$ SPC provides an objective measure of capacity and demand by providing a visual representation of the performance of a process, showing data points against calculated upper and lower control limits (UCL and LCL). We set the UCL and LCL at 3 SDs from the mean.

Capacity (staff resources) is typically set at the mean of the demand; this means that $50 \%$ of the time there will be more demand than capacity. However, this policy results in a delay for some patients receiving attention and consequently queuing.

Resourcing capacity at the UCL would prevent delay. Nevertheless, due to the large variation in demand this would lead to over resourcing and inefficient utilisation of available staff. Therefore, it is generally recognised that, to optimise utilisation of staff resources (Capacity) and ensure that there is flexibility in the system in the event of heightened demand, while also avoiding wastage at times of reduced workload, the 80th centile (rather than UCL or LCL) of the demand variation should be used to determine capacity.

\section{RESULTS}

A total of 1160 of the potential $1568(74 \%)$ scoring sheets were completed between June 2009 and July 2010. The average staff number throughout the year on any shift was 7 (range 3-11). Dependency scores varied between different days of the week and at different times of the day. The average dependency score was 7 (range 1-14). Weekend demand was lower compared with the weekday activity. The 80th centile of midwifery staff 


\begin{tabular}{|c|c|c|}
\hline CATEGORIES & POINTS & DEFINITION \\
\hline & 0.25 & - Propess (low risk minimal care on MAU) \\
\hline & 0.5 & - Propess (high risk on Delivery Suite) \\
\hline & & - Spontaneous labour No risk factors \\
\hline I. \& II. & 1 & - With or without ECTG \\
\hline & & - All of the above with the addition of:- \\
\hline III. & 1.2 & - Induction of labour \\
\hline & & - Preterm birth \\
\hline & & -Assisted delivery \\
\hline & & - $3^{\text {rd d }}$ degree tear / complicated repairs \\
\hline & & - All of the above with the addition of:- \\
\hline IV. & 1.3 & - Epidural anaesthesia \\
\hline & & - More complicated cases requiring FBS \\
\hline & & -Elective caesarean sections \\
\hline & & - Mother and baby require a very high \\
\hline V. & 1.4 & degree of support or intervention (medical \\
\hline & & (obstetric complications) \\
\hline & & - Retained placenta \\
\hline & & - General anaesthetic \\
\hline & & - All emergencies caesarean sections \\
\hline & & - All multiple births Intensive care not \\
\hline & & accounted for by any other factor \\
\hline & & - Blood transfusions \\
\hline & & -Adverse outcomes (stillbirths/TOPs) \\
\hline
\end{tabular}

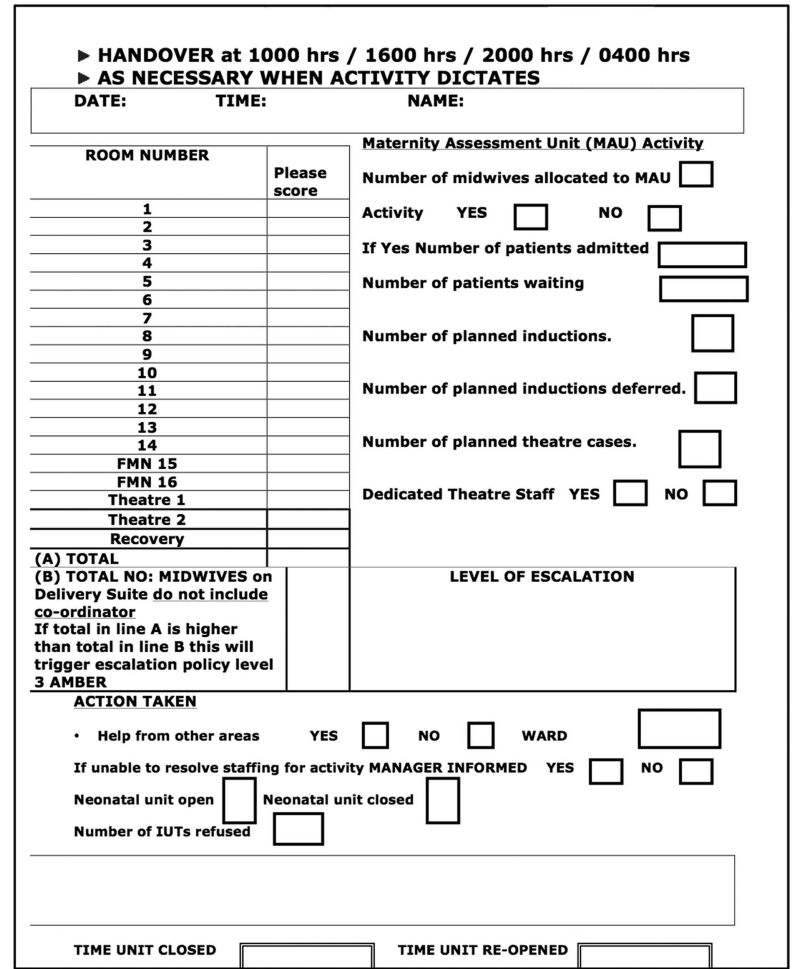

Following delivery all women on labour ward will continue to contribute to the overall score for at least one hour according to their individual care needs

Figure 1 Dependency scoring system and scoring sheet. ECTG, electronic cardiotocogram; ECV, external cephalic version; FBS, fetal blood sampling; TOP, termination of pregnancy; FMN, forget me not (bereavement room for women with fetal loss).

available and patient dependency scores for each shift by weekdays are presented in figure 2 .

There was heightened clinical activity midweek throughout the year. The 22:00 shift showed persistently higher dependency scores compared with the 10:00 shifts; the latter were normally well staffed.

The unit escalation level according to the scored sheets throughout the study period is presented in figure 3. The unit reached escalation level 4 on 17 occasions in the 12-month period analysed. A level 4 escalation triggered senior clinical and managerial staff involvement to mobilise midwives from other areas to alleviate the risk of potential unit closure. The unit closed on four occasions during the study period and this ranged from 3 to a maximum 9 hours per event. We can only speculate that closure happened in spite of the above measures because it was still not feasible to downgrade the level of escalation.

Control charts are suitable for normal distributions where $99.72 \%$ of the variation falls between 3 SDs above and below the mean. This was plotted (count) and found to be the case as seen in figure 4 . Using the

Table 1 Escalation level determined by ration of dependency score to number of staff per shift

\begin{tabular}{|c|c|c|c|}
\hline $\begin{array}{l}\text { Staff number (C)-dependency } \\
\text { score (D) }\end{array}$ & $\begin{array}{l}\text { Colour } \\
\text { code }\end{array}$ & $\begin{array}{l}\text { Escalation } \\
\text { level }\end{array}$ & Clinical impact \\
\hline $\begin{array}{l}2 \text { or more staff }>\text { dependency } \\
\text { score } \\
\text { C-D } \geq 2\end{array}$ & Green & Level 1 & Uncompromised staffing levels \\
\hline $\mathrm{C}-\mathrm{D}=1$ & Yellow & Level 2 & Near full utilisation of available capacity \\
\hline $\begin{array}{l}\mathrm{C}=\mathrm{D} \\
\text { or } \mathrm{C}-\mathrm{D}=-1 \text { but likely to improve } \\
\text { within } 2 \mathrm{~h}\end{array}$ & Amber & Level 3 & $\begin{array}{l}\text { The unit cannot accommodate in utero transfers or planned } \\
\text { admissions }\end{array}$ \\
\hline $\begin{array}{l}\mathrm{C}-\mathrm{D} \leq-2 \\
\text { or } \mathrm{C}-\mathrm{D}=-1 \text { but unlikely to } \\
\text { improve within } 2 \mathrm{~h}\end{array}$ & Red & Level 4 & $\begin{array}{l}\text { Senior staff involvement to mobilise staff from other areas to } \\
\text { alleviate potential unit closure }\end{array}$ \\
\hline
\end{tabular}



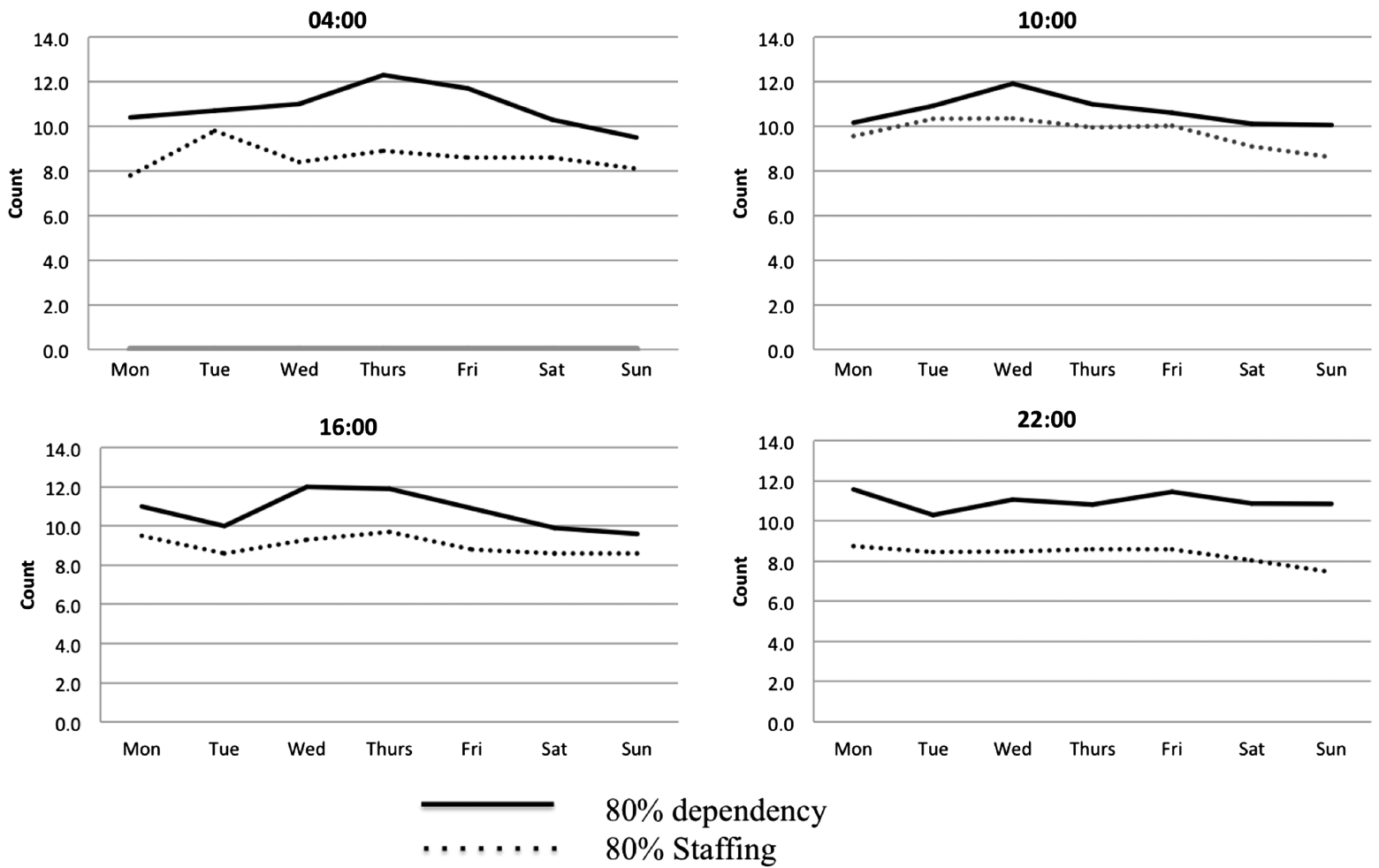

Figure 2 The 80th centile dependency scores (demand) and staff numbers (capacity) throughout the studied period for the four shift times by week days.

formula: (UCL-LCL) $\times 80 \%$ ) + LCL ${ }^{12}{ }^{13}$ the 80 th centile of the demand variation was calculated to be 11 .

\section{DISCUSSION}

Midwifery staffing shortage is an ongoing concern nationally. In spite of a rise in midwifery recruitment, this increase in capacity has not kept pace with the increasing demands on maternity services. Moreover, the imposition of European working time directives and reductions in the number of doctors in training necessitates team working changes and the adoption of different organisational models. 1415

There has been a rise in birth rate especially in women with co-morbidities such as obesity, older women and

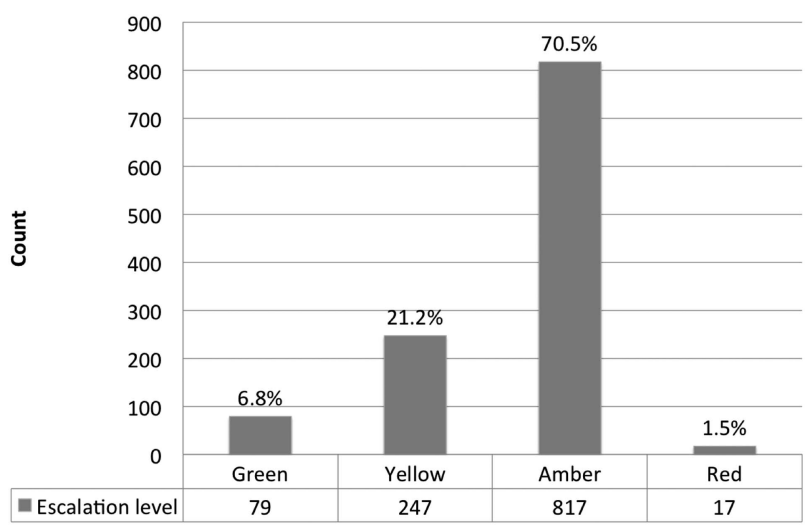

Figure 3 Unit escalation level throughout the study period. those born outside the UK. Therefore, it is not surprising that one of the key recommendations of the King's Fund inquiry into the safety of maternity services was to ensure that maternity units have structures in place to gather data on their unit's activity and demand. ${ }^{16} 17$ The issue of safe staffing levels has never been under the spotlight more than following the publication of the Francis report which recommended that NICE develops 'evidencebased tools for establishing the staffing needs of each service' in the NHS. ${ }^{18}$ It is recognised that out-of-hours obstetrics is a major source of risk. Data from several studies have shown higher rates of neonatal death in women who deliver out of hours; variations in staff deployment have been implicated as one of the causes for this disparity. ${ }^{19-23}$ Staff planning and deployment in any acute service faces the challenge of fluctuating demand. Various dependency scores have been developed and utilised in acute medicine, especially accident and emergency departments and intensive care units. ${ }^{24-}$ ${ }^{27}$ However, DS is unique in that it has to deal with a combination of a physiological process that is at best changeable and acute 'unpredictable' potentially serious medical and surgical demands that can rapidly change over a relatively short period of time while catering for relatively predictable elective work running in parallel.

Staff deployment on DS has customarily been determined by resource allocation and 'average' patient turnover retrieved from historic data. The average number of staff available per shift on DS throughout the monitored year was seven, which was identical to the average dependency score for the monitored shifts during the 


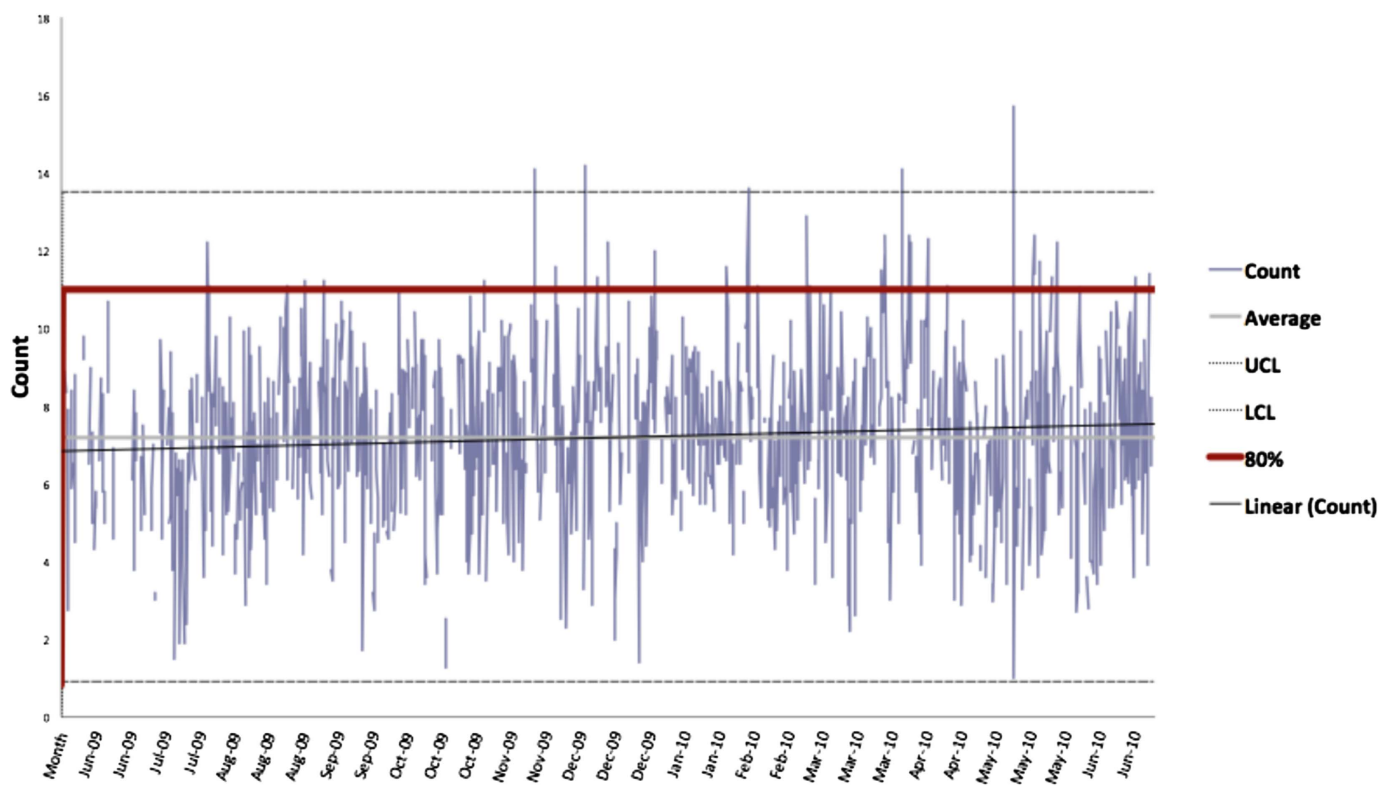

Figure 4 Dependency scores for the study period (UCL, upper control limit; LCL, lower control limit).

same time period. This would imply that staffing levels were appropriate for the studied period. However, calculating staff numbers based on the average activity runs the risk of failing to meet the demands on $50 \%$ of the occasions. This is due to the fact that averages tend to smoothen out the peaks and troughs (variations) in the activity pattern and hence do not portray demand in real time. Indeed this is demonstrated in figure 4, where the dependency scores for our DS were plotted for the whole year on a control chart depicting the variation in the activity on DS. Basing staffing levels on averages would have entailed deployment of seven midwives per shift to staff the DS. Interestingly, as explained above, this would result in staff shortages over half the times above and below this average (red line). Using SPC, we were able to monitor and study demand by drawing the data on a control chart (figure 4). Determining staffing levels based on the UCL ensures that the calculated number will be safe to cover $99.7 \%$ of the expected demand. However, this can potentially lead to problems of overresourcing and wastage, this being the main driver to set the capacity to $80 \%$ of the demand. This level optimises staff usage, prevents undue resourcing while allowing flexibility in the system to deal with variations in the day-to-day activity with a consequent improvement in the safety environment on labour ward. This concept was originally generated from the queuing theory postulated by AK Erlang, a Danish telecommunication engineer. ${ }^{28}$ Since its conception, the model has now been widely applied in different contexts including traffic engineering, factories, computing and shops. There is an increasing use of this capacity/demand model in heathcare to compute resource allocation on wards, outpatient clinics and accident and emergency departments. ${ }^{28-30}$ This study demonstrates that DS are not an exception.

Following the feeling among staff members that some midwives overestimated the dependency score with a consequent increase in occasions of and severity of levels of escalation, the comparison of midwifery versus investigator coding demonstrated that there was an element of truth in this perception. However, midwives also seemed to underestimate activity when shifts were very busy and should have been categorised as escalation level 4 (red) where they were categorised as level 3 (amber). We can only speculate the reasons for these variations, which could be related to awareness that the high level of activity was transient and did not warrant evoking the level 4 escalation procedure. It is also possible that staff were consciously or unconsciously trying to avoid the administrative complexities of documenting a level 4 escalation and the potential of unit closure or that some staff members find it easier to choose the middle category rather than the extremes. Nevertheless, this should not have been an issue with employment of a well-defined objective scoring system.

There are some potential limitations to our study. The scoring sheets were introduced after an initial pilot and staff training. Nonetheless, we did not evaluate the impact of this training on the usability of the scoring system or inter-rater variability. However, this was introduced as a departmental quality and safety intervention and the scoring system was deemed easy to follow with simple instructions especially as it was largely based on the $\mathrm{BR}^{+}$scoring system which most midwives were familiar with. Missing data were identified in $26 \%$ of the shifts overall. Unfortunately, we did not collect information regarding reasons for not completing a score sheet; hence, our proposed reasons for non-completion are only speculative. It is plausible that the reasons for missing data are related to lack of time to complete the scoring sheets because of workload, concerns that consistently low activity scores may compromise the number of staff allocated to future shifts or resistance to what could be perceived as a paper filling exercise. Indeed, if 
true, some of these reasons could be a source of bias. However, It is important to note that the percentage of missing shifts was not uniformly distributed between the four time points with the 04:00 shift showing the maximum deficit of $47 \%$. This issue could potentially be a source of bias; however, our sample was representative and consistent enough throughout the studied period for us to be confident in our assumptions. This view is further supported by $\mathrm{NPSA}^{9}$ recommendation that plotting of activity over a 3-month period would give sufficient information to extrapolate the data for the whole year. Moreover, this study supports the view echoed in the recent NICE guideline relating to safe staffing which stresses that there is no single optimal nurse-to-patient ratio that can be applied across the board; however, each ward has to determine safe levels of staffing depending on their individual daily circumstances to ensure safe patient care. ${ }^{31}$

\section{CONCLUSION}

This study highlights the feasibility of using a simple tool to determine the level of escalation on DS based on an objective scoring system that takes into account capacity and demand. Moreover, this tool can be used to determine the appropriate staffing levels required for the safe and efficient service delivery on a labour ward. However, further work is required to assess stakeholders acceptability, inter-rater reliability and escalation trigger levels in different types of maternity units prior to wider use.

Acknowledgements The authors would like to thank S Johnston and $\mathrm{H}$ Entwistle for data storage and handling and the labour ward midwives, particularly $\mathrm{J}$ Jenkinson and the shift leaders for maintaining a fairly high rate of form completion and for their support during the study period. We would also like to thank Lucy Ingram, Research Midwife for her valuable help preparing the manuscript for submission.

Contributors KMKI and BW conceived the idea. JCC, KMKI, KM and BW were all involved in study design. IS imputed data and wrote the manuscript with critical input from all other authors. MR, JB, IS and KMKI carried out data analysis.

Funding This research received no specific grant from any funding agency in the public, commercial or not-for-profit sectors.

Competing interests None.

Provenance and peer review Not commissioned; externally peer reviewed.

Data sharing statement No additional data are available.

Open Access This is an Open Access article distributed in accordance with the Creative Commons Attribution Non Commercial (CC BY-NC 4.0) license, which permits others to distribute, remix, adapt, build upon this work noncommercially, and license their derivative works on different terms, provided the original work is properly cited and the use is non-commercial. See: http:// creativecommons.org/licenses/by-nc/4.0/

\section{REFERENCES}

1. Pietersen C. Job satisfaction of hospital nursing staff. SA J Human Resour Manag 2005;3:6.

2. Healthcare Commission. Towards better births: a review of maternity services in England. England, 2008:96.
3. Care Quality Commission. Market report. England, 2012:36.

4. Royal College of Obstetricians and Gynaecologists, Royal College of Midwives, Royal College of Anaesthetists, Royal College of Paediatrics and Child Health. Safer childbirth. Minimum standards for the organisation and delivery of care in labour. London, UK, 2007:89.

5. National Institute for Health and Clinical Excellence. Intrapartum care: management and delivery of care to women in labour. Clinical guidelines. 2007:69.

6. Nasr A, Reichardt K, Fitzgerald K, et al. Impact of emergency admissions on elective surgical workload. Ir J Med Sci 2004:173:133-5.

7. Ball JA, Washbrook M. Birthrate Plus; a framework for workforce planning and decision making for midwifery services. Books for Midwives Press: Elsevier Press, 1996.

8. Ball JA, Bennett $B$, Washbrook M, et al. Birthrate Plus programme: a basis for staffing standards? Br J Midwifery 2003;11:264-6.

9. National Patient Safety Agency. A guide to using the Intrapartum Scorecard. 2010:21.

10. Mathew D, Dougall A, Konfortion J, et al. The Intrapartum Scorecard: enhancing safety on the labour ward. Br J Midwifery 2011;19:578-86.

11. Thor J, Lundberg J, Ask J, et al. Application of statistical process control in healthcare improvement: systematic review. Qual Saf Health Care 2007;16:387-99.

12. Silvester K, Steyn R. Why do we get queues and waiting lists? 2008:37.

13. NHS Institute for Innovation and Improvement. Matching capacity and demand. Improvement Leaders' Guide. 2005.

14. Cantwell R, Clutton-Brock T, Cooper G, et al. Saving Mothers' Lives: reviewing maternal deaths to make motherhood safer: 2006-2008. The Eighth Report of the Confidential Enquiries into Maternal Deaths in the United Kingdom. BJOG 2011:118(Suppl 1):1-203.

15. Hurst K. Evaluating the strengths and weaknesses of NHS workforce planning methods. Nurs Times 2010;106:10-14.

16. Sandall J, Homer C, Sadler E, et al. Staffing in maternity units: getting the right people in the right place at the right time. UK: Kings Fund, 2011:63.

17. King's Fund. Safe Births: Everybody's business. Independent inquiry into the safety of maternity services in England. 2008:146.

18. Report of the Mid Staffordshire NHS Foundation Trust Public Inquiry -Executive summary. London: 125.

19. Luo ZC, Karlberg J. Timing of birth and infant and early neonatal mortality in Sweden 1973-95: longitudinal birth register study. BMJ 2001;323:1327-30.

20. Luo ZC, Liu S, Wilkins R, et al. Risks of stillbirth and early neonatal death by day of week. CMAJ 2004;170:337-41.

21. Pasupathy D, Wood AM, Pell JP, et al. Time of birth and risk of neonatal death at term: retrospective cohort study. BMJ 2010;341: c3498.

22. Gould JB, Qin C, Chavez G. Time of birth and the risk of neonatal death. Obstet Gynecol 2005;106:352-8.

23. Heller G, Misselwitz B, Schmidt S. Early neonatal mortality, asphyxia related deaths, and timing of low risk births in Hesse, Germany, 1990-8: observational study. BMJ 2000;321:274-5.

24. O'Brien A, Benger J. Using patient dependency to calculate staffing needs in A/E. Nurs Times 2008;4:3.

25. Ashcroft B, Elstein M, Boreham N, et al. Prospective semistructured observational study to identify risk attributable to staff deployment, training, and updating opportunities for midwives. BMJ 2003;327:584

26. Smith J, Forde V, Goodman M, et al. How to keep score of acuity and dependency. Nurs Manag (Harrow) 2009;16:14, 16-9.

27. Crouch R, Williams S. Patient dependency in the emergency department (ED): reliability and validity of the Jones Dependency Tool (JDT). Accid Emerg Nurs 2006;14:219-29.

28. Mehandiratta R. Applications of queueing theory in health care. Int $J$ Comput Bus Res 2011;2:11.

29. Perla RJ, Provost LP, Murray SK. The run chart: a simple analytical tool for learning from variation in healthcare processes. BMJ Qual Saf 2011;20:46-51.

30. Cayirli T, Veral E. Outpatient scheduling in health care: a review of literature. Oper Manage 2003;12:30.

31. National Institute for Health and Care Excellence. Safe staffing for nursing in adult inpatient wards in acute hospitals. Safe staffing guideline 1,2014 